\title{
Pyrolysis yields of tobacco crop residue as a potential alternative fuel source
}

\author{
Widya Wijayanti*, Mega Nur Sasongko and Musyaroh \\ Department of Mechanical Engineering, Energy Conversion, Brawijaya University, Malang, Indonesia \\ *Corresponding Author: widya_dinata@ub.ac.id
}

Submitted: $25 / 06 / 2020$

Revised: $\quad 21 / 12 / 2020$

Accepted: 28/12/2020

\begin{abstract}
This study aims to utilize the tobacco crop residue to generate a high economic value for the energy sector. In general notion, tobacco crop is burned as a conventional fuel at low prices; however, in this research, tobacco crop residue was processed through pyrolysis in the form of pyrolysis products (liquid and solid yields) providing a promising alternative fuel fulfilling the standardized fuel properties. The pyrolysis was conducted at a laboratory-scale real pilot plant experiment at a fixed bed reactor and was operated at temperature of around $350{ }^{\circ} \mathrm{C}$ to $650{ }^{\circ} \mathrm{C}$ for 2 hours to navigate the most optimum product. Further, the products comprising char (solid yield) and tar (liquid yield) were investigated by measuring their properties, which include heating value, flash point, viscosity, density, and char yields' morphology. The measurement results indicated that the heating value of tobacco crop residue from pyrolysis process significantly escalated to $300 \%$ compared to that of tobacco crop residue before pyrolysis process. Similarly, several tar properties indicated the liquid fuel standard such as kerosene. Additionally, another product in the form of solid yields is proved to be utilized as a smart material besides having a higher heating value over coal, due to the high-quality carbon specifications. However, further processing is encouraged to navigate the possibility of solid yields into activated carbon.
\end{abstract}

Keywords: Pyrolysis; Tobacco; Alternative Fuels.

\section{INTRODUCTION}

Circulating debates regarding limited energy, environmental pollution, global warming, and environmental changes have been resonant in current decades, encouraging the search for energy sources to address the aforementioned issues. Effort includes the navigation of appropriate fuel to substitute fossil fuels by converting biomass into biofuel through the pyrolysis process. Prior studies (Biswas et al., 2017; Dhyani et al., 2017; Li et al., 2020; Pena et al., 2020; Qiang et al., 2009; Sfakiotakis et al., 2018; Silvy et al., 2018; and Wang et al., 2009) had been devoted to examine the advantage of pyrolysis process engaging various types of plants. Pyrolysis process typically utilizes waste or disadvantaged material of agriculture harvesting yields such as tobacco crop residues.

The researchers of this study asserted several reasons for tobacco conversion into biofuel, which were due to highbiomass crop, abundant availability in post harvesting, abundant supply of organic waste, not a food source, and high feasibility of heating value. In previous discourse, tobacco crop wastes were merely stacked for animal feed or burnt for next planting preparation. Hence, the conversion process is required despite its profound potential as an alternative fuel to reduce the volume of biomass wastes and to destroy the pathogenic content.

Several preliminary studies have been conducted in relation to the conversion process with future potentiality through pyrolysis process. However, relevant studies (Yan et al., 2018; Gao et al., 2013; Torikaiu et al., 2005; and Wu et al., 2015) were limited which engaged the experiments on tobacco pyrolysis, by utilizing tobacco crop residue 
as biofuel. Despite the pivotal urgency for fuel substitution requirements, fuel combustion devices are required to meet the standards to compare the properties among fuels and their substitutions. One of the standards includes the fulfilment of physical and chemical properties to ensure that fuel substitution is proper for the standard engine usage. Hence, this study aims to examine the physical properties of tobacco residue through pyrolysis products as the proposed candidate for fuel substitution.

This study investigates both the quantity and quality of pyrolysis products. The quantity of pyrolysis yields involves mass and density of the product yields, while the quality of pyrolysis involves physical properties of the products at each pyrolysis setting temperature due to the novelty of this study in navigating the tobacco's potentiality as a biofuel. The tobacco crop residues consist of several chemical compositions, such as $49 \% \mathrm{C}$ and $44 \% \mathrm{O}$ in tobacco stem, while $43 \% \mathrm{C}$ and $50 \% \mathrm{O}$ in tobacco leave are the majorities of elements. To navigate the high potential of tobacco as a fuel candidate, comparisons are performed with the constituent compounds of coal due to higher proportion of $\mathrm{C}$ element at $70 \%$, and fewer proportion of $\mathrm{O}$ element at $9 \%$.

In addition, this study observes whether the results of the tobacco pyrolysis are persuasive to substitute coal consumptions. The conversion process of tobacco into fuel involves pyrolysis process which generates products in the form of char and tar yields. In contrast, the char yields are proved to have the potential of becoming solid fuel or smart Carbon material, like the activated Carbon (Li et al., 2020; Pena et al., 2020). Meanwhile, another product such as tar yields has several potential properties to be used as a liquid fuel, food preservative, or ingredient for aromatherapy. Furthermore, pyrolysis process is performed to investigate the effectiveness of biotechnology process, including the probable utilization of tobacco crops and tobacco harvest. It is assumed that the pyrolysis process improves and intensifies the tobacco's value as a crop by minimizing the tobacco crop harvest waste. This research, thus, limits the observation into the solid and liquid yields of tobacco crop residue to produce alternative fuels.

\section{METHODS}

The tobacco crop residues (tobacco stems and leaves) were obtained from Tarutama Nusantara Agriculture Company, Jember, Indonesia, to be utilized as the samples for this experiment remained from the tobacco harvesting for cigarettes. The weight of each sample was around $100 \mathrm{~g}$, and the size was between $5 \mathrm{~mm}$ and $10 \mathrm{~mm}$. Before the pyrolysis process, the samples were dried and equilibrated at a constant temperature $100{ }^{\circ} \mathrm{C}$ and a constant humidity for 1 hour inside an oven. After the drying process, the samples were tested for their moisture content until achieving $2 \%$ water content.

Figure 1 illustrates the experimental apparatus for pyrolysis process as prepared in a laboratory-scale pyrolysis furnace to pyrolyze the tobacco in a real pilot plant experiment by utilizing an electrical heater ( 7 and 8$)$. The furnace (5) was designed as a fixed bed reactor, regarded as an open closed system to process the tobacco samples in the absence of $\mathrm{O}_{2}$. The reactor has a weight capacity of around $100 \mathrm{~g}$ for tobacco. Further, the reactor is able to be operated at the desired temperature up to $800{ }^{\circ} \mathrm{C}$. In addition, a thermocontroller is provided (9) to set the pyrolysis temperature and monitor the pyrolysis temperature inside the wall as measured by a thermocouple (6).

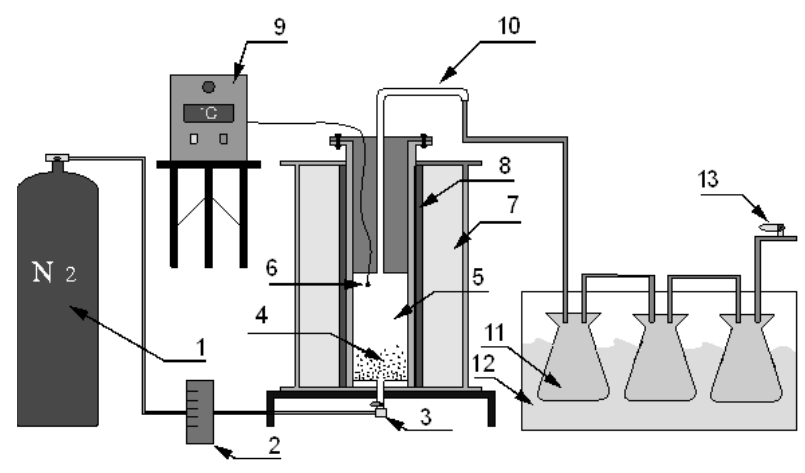

Figure 1. Experimental apparatus of tobacco pyrolysis. 
The experiment of this study includes all of tobacco samples (stems and leaves) as feedstock. Some setting temperature variations (9) were modified in the experiment to examine their effect on the pyrolysis products, such as char and tar in terms of quantity and quality. Initially, the tobacco samples (4) were dried for an hour at $100{ }^{\circ} \mathrm{C}$ inside an oven. Afterwards, the samples' moisture content was measured by utilizing a moisture analyzer (type: MOC$120 \mathrm{H})$. The sample was each weighted around $100 \mathrm{~g}$, later inserted into the furnace. After closing the furnace reactor, Nitrogen gas (1) was flowed and was measured by employing flowmeter (2) to suppress Oxygen level until the furnace contained $2 \%$ Oxygen. The nitrogen valve (3) was further switched off and the furnace was set at the desired pyrolysis temperatures. In this study, the researchers established the various pyrolysis setting temperatures at $350{ }^{\circ} \mathrm{C}, 450{ }^{\circ} \mathrm{C}$, $550{ }^{\circ} \mathrm{C}$, and $650^{\circ} \mathrm{C}$. The pyrolysis process underwent for 2 hours. For the liquid yield, the tar flowed out through (10) and was trapped in the glass beakers (11) inside an ice-cold bath (12). On the other hand, the solid yield such as the biomass remains (solid yields as char) was left inside the furnace to be removed once the furnace temperature had reached ambient temperature. The gas yields flew to the surrounding, though they were not examined in this study.

After accomplishing the pyrolysis process, the pyrolysis products such as char (solid yield) and tar (liquid yield) were measured to observe the quantity of pyrolysis yields (including mass, volume, and density). In addition, the yields' physical properties were measured, which included heating value (through Parr 6050 Calorimeter), flash point (through SYD 216-1 Pensky-Martens closed cup flash point tester), viscosity (through LEYBOLD, type: ABR NL 90212), and density (through electrical balance ACIS BC 500) to explain any potential properties such as char mass and volume within tobacco crop possesses as a substitute fuel. The char products were also analyzed by utilizing SEMEDX (FEI, type: Inspect-S50) to investigate char morphology and substances.

\section{RESULTS AND DISCUSIONS}

Before conducting the pyrolysis process, prior steps are encouraged to navigate the physical property such as heating value of several energy source types as well as to perform a comparison with those of tobacco crops. The heating value of tobacco is quite high around $4295 \mathrm{cal} / \mathrm{g}$, which is higher than wood and lower than coal. Until now, the best solid fuel is coal, so the energy conversion of any material and the desired properties of other materials are close to the coal properties.

In addition to the comparison of the heating values, the comparison of the composition of the biomass as a candidate fuel is also very important to measure. This is because these complex compounds of some biomass will be converted to the simpler compounds. It means that the pyrolysis process carried out will decompose the compounds that are quite complex by having long Carbon compounds into short Carbon compounds. Several studies (Meneses et al., 2017; Dhyani et al., 2017; \& Silvy et al., 2018) compared the components of tobacco stems and leaves to other biomass feedstocks, such as hardwood, corn stalk, bagasse, and mahogany wood to similar hydrocarbon components consisting of lignocellulosic components such as cellulose, hemicelluloses, and lignin. Hence, it is evident that despite similar structure-forming content, the percentage of contents is different. During the pyrolysis process, differences in the component will lead to differences in the process, such as in tobacco which is more easily decomposed compared to mahogany wood, even though corn stalk is much more easily decomposed than tobacco because it contains more cellulose. As acknowledged, cellulose is the most easily decomposed compound compared to hemicelluloses and lignin. Hence, tobacco is regarded as a potential feedstock material for pyrolysis process in the production of prospective fuels. Accordingly, the percentage of cellulose, hemicelluloses, and lignin contained in tobacco is suggested as a potential fuel feedstock through appropriate process for fuel production.

The performed experiment indicated that solid yields (char as solid fuel and smart material) and liquid yields (tar as liquid fuel) were also produced through pyrolysis process.

\section{CHAR YIELD AS A POTENTIAL SOLID FUEL AND SMART MATERIAL}

Several pyrolysis products in the form of solid yield (char) are examined. Char yields are proved to contain fixed carbon with specific heating values. Prior to examining the heating value of char, the char yields at various pyrolysis temperatures are recommended to be initially observed. 


\section{The mass and density of char yields}

Figure 2 illustrates that prior to pyrolysis process, the biomass has a weight of 100 grams. After measuring the mass and the volume yields of solid products, the apparent density was calculated with initial density at around $0.15 \mathrm{~g} / \mathrm{ml}$ as determined in Figure 3. The result depicts that the mass and volume of char decrease as the pyrolysis temperature increases due to the biomass decomposition as a result of thermal cracking [Ma, X. et al., 2020]. Hence, at a high-temperature pyrolysis process, the biomass decomposition involving molecule bonds is easier to perform, breaking down the biomass into char, tar, and gas, despite the fact that the gaseous products were not observed in this study. As a result of thermal cracking, higher temperature generates more tar yields as depicted in Figure 8 and Figure 9. Additionally, the results depict that the pyrolysis process will leave fewer solid yields.

If tobacco leaves are compared to the stems, more char yields will be produced by tobacco stems than by tobacco leaves due to the differences in lignin content between tobacco stems and leaves.

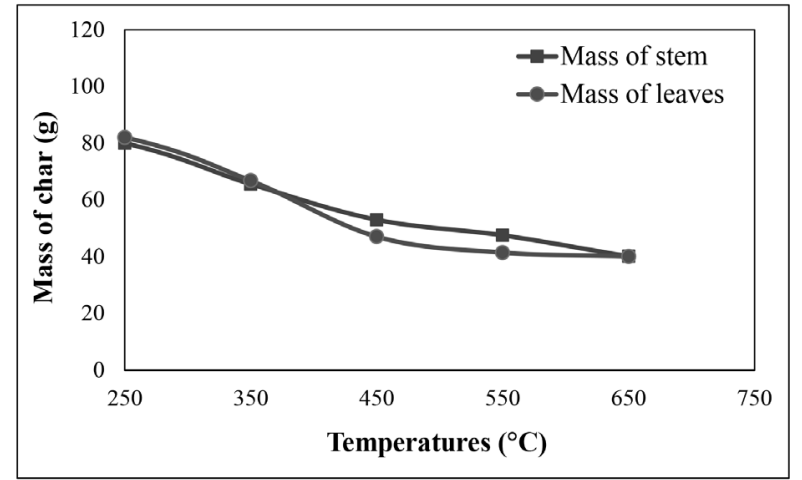

Figure 2. Mass of char yields.

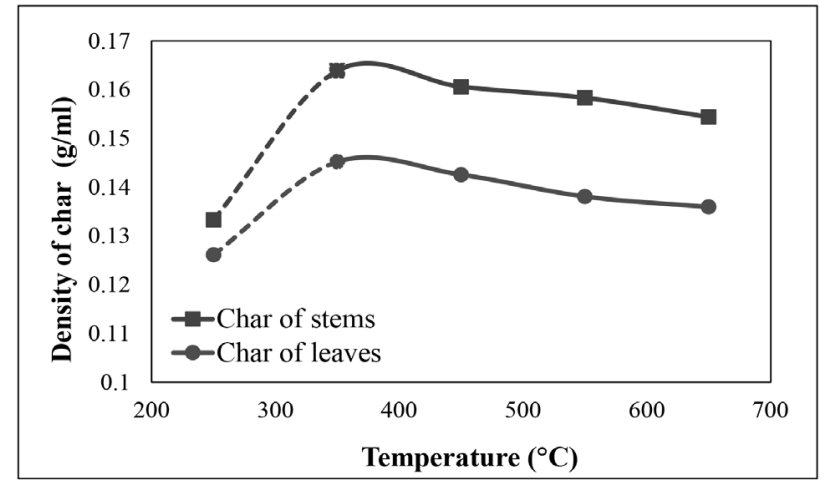

Figure 3. Density of char yields.

The lignin content of tobacco stems is $15 \%$ greater when compared to tobacco leaves, which is only $12.1 \%$ [Dhyani et al., 2017]. Lignin becomes one of the biomass compounds that is difficult to break due to its complex molecules which are cross-linked with different chemical bonds. As a result, greater content of lignin in biomass results in greater remaining char. In addition, the result illustrates the similar decreasing pattern in mass and volume of char yields.

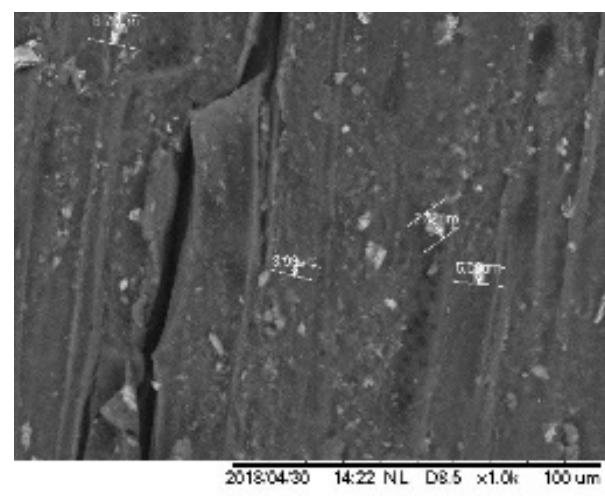

vormus 2

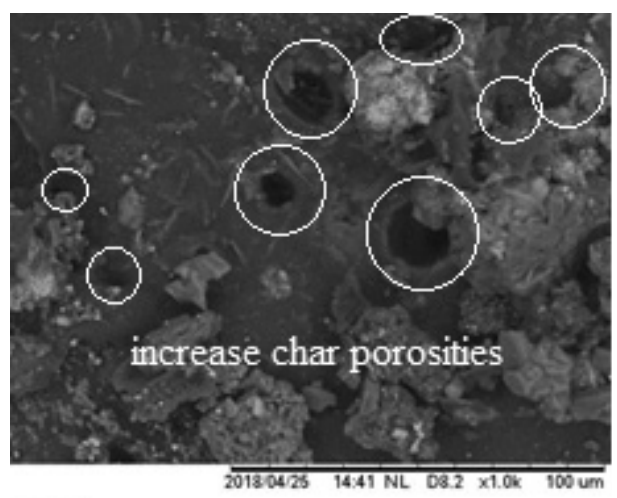

(b)

vormula 2

(a)

Figure 4. SEM images of tobacco leaves (a) before pyrolysis and (b) after pyrolysis at $\mathrm{T}=650^{\circ} \mathrm{C}$. 
However, there were some differences in the decrease of mass between leaves' char and stems' char. If it elucidates the apparent densities, the volume of tobacco leaves' char was more than that of tobacco stems' char. In reference to the apparent densities, it is inferred that the char in tobacco leaves has a greater volume than that in tobacco stems. On the other hand, the char in tobacco stems appears smaller than that in tobacco leaves. Such differences appear due to different porosity of the two, illustrated by SEM-EDX visualization in Figure 4 and Figure 5. The effect of change in porosity will affect the apparent density of char, further determining the char porosity as depicted in Figure 3, illustrating the apparent density of char yields during the pyrolysis process. Thus, it is visible that the density of char in tobacco stems is higher than that of tobacco leaves.

In terms of char density, it is apparent that char in tobacco stems has a greater density than char in tobacco leaves. The results of SEM-EDX explain that the char in tobacco stems has greater apparent density than that in tobacco leaves. As the pyrolysis temperature increases, the apparent density of char decreases. When the mass and volume of char decrease in proportion to the increasing temperature, the decreasing of char mass is greater than the char volume due to greater char porosities.

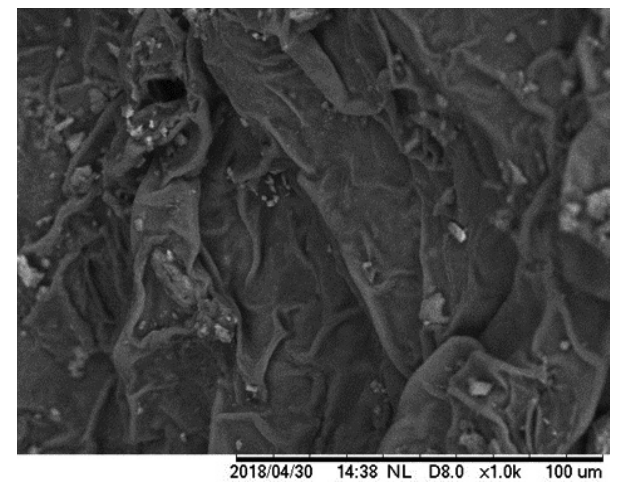

vormula 2
$2018 / 04 / 30 \quad 14: 38$ NL $\quad$ D8.0 $\times 1.0 \mathrm{k} \quad 100 \mathrm{um}$

(a)

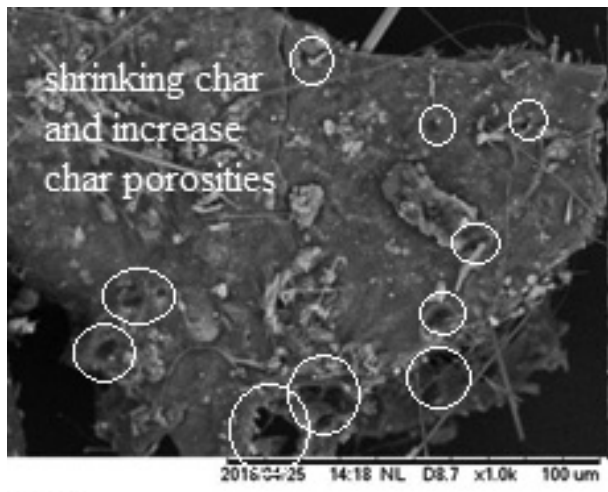

vermula 2

(b)

Figure 5. SEM of tobacco stems (a) before pyrolysis and (b) after pyrolysis at $\mathrm{T}=650^{\circ} \mathrm{C}$.

The SEM results indicate that the biomass morphology before and after the pyrolysis is related to char geometry, physical properties, and chemical properties. Hence, the apparent densities indicating the porosities of the tobacco leaves are greater than those of the tobacco stems. Additionally, the size of leaves' pore appears larger than that of the stems' pore, leading to greater volume at the end of the pyrolysis process. This result indicates that the change in leaves volume after pyrolysis is much greater than the change in stem volume. In the same mass, due to the greater leaves' porosities, the leaves' volume is also higher when compared to the stem, leading to apparent density indicated by greater ratio between the mass and volume of tobacco stems than that in tobacco leaves. Accordingly, within similar pyrolysis temperature, the volume of tobacco stem after pyrolysis is much smaller than that of tobacco leaves.

The size of porosity change due to pyrolysis is determined by the content of compounds in both the tobacco stem and leaves. The cellulose and hemicelluloses are decomposed at low temperatures. The tobacco leaves thus will decompose faster than the tobacco stems due to having more cellulose and hemicelluloses. The bonds among tobacco leaves' molecules are much weaker than those in the tobacco stems. In contrast, the tobacco stems have greater lignin content than those in the tobacco leaves, hindering the decomposition which results in larger leaves' cavities due to pyrolysis process. 


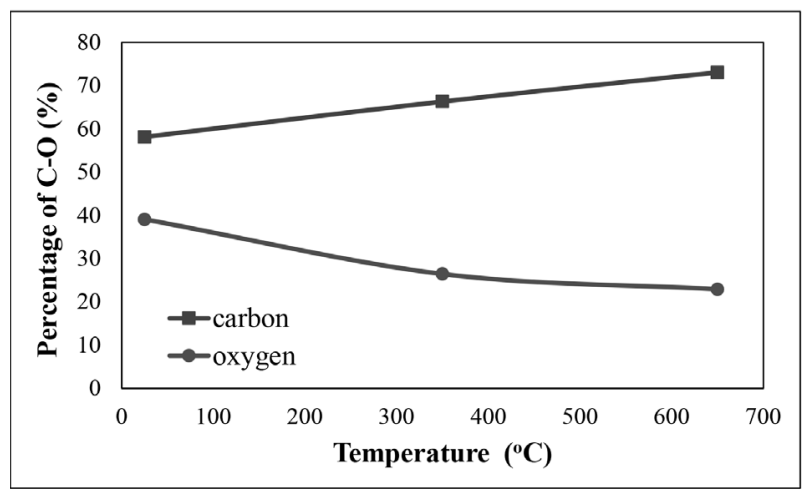

Figure 6. Comparison of Carbon and Oxygen percentages in stem yields.

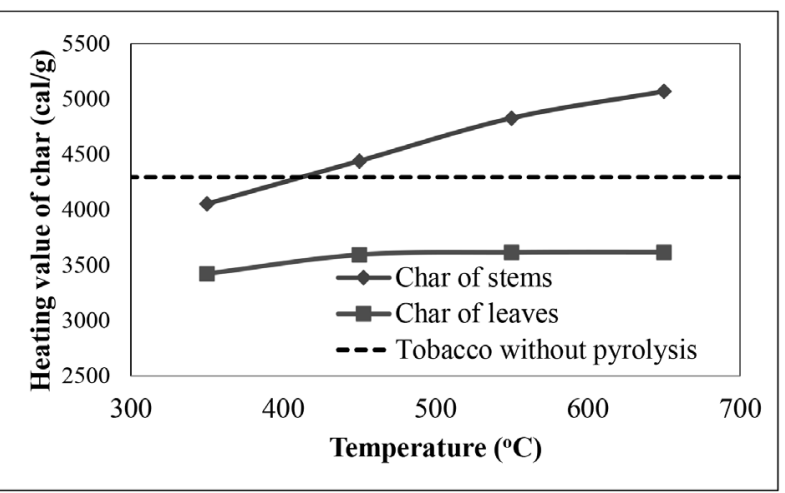

Figure 7. Heating values of char yields.

Figure 4(a) and Figure 5(a) present the SEM results for the biomass in tobacco stems and leaves, respectively, before the pyrolysis process in which the particles are still intact due to the absence of decomposition process. On the other hand, Figures 4(b) and 5(b) depict the SEM results of char after pyrolysis at $650{ }^{\circ} \mathrm{C}$, where the leaves and stems particles have begun to shrink, and the cavities become larger than before pyrolysis process. This result is due to the fact that the biomass component has almost completely decomposed with changes in the tobacco constituent elements.

Table 1. Percentages of elements in solid yields by EDX measurements.

\begin{tabular}{|c|c|c|c|c|c|c|c|c|c|c|}
\hline \multirow{2}{*}{ T pyrolisis } & \multicolumn{4}{|c|}{ Stems (\%) } & \multicolumn{5}{c|}{ Leaves (\%) } \\
\cline { 2 - 12 } & $\mathrm{C}$ & $\mathrm{O}$ & $\mathrm{Si}$ & $\mathrm{S}$ & $\mathrm{Ca}$ & $\mathrm{C}$ & $\mathrm{O}$ & $\mathrm{Si}$ & $\mathrm{S}$ & $\mathrm{Ca}$ \\
\hline Before & 58,135 & 39,065 & 0,065 & 0,123 & 0,342 & 58,135 & 39,065 & 0,065 & 0,123 & 0,342 \\
\hline $350^{\circ} \mathrm{C}$ & 66,308 & 26,429 & 0,574 & 0,107 & 0,585 & 62,874 & 29,672 & 0,305 & 0,167 & 2,249 \\
\hline $650^{\circ} \mathrm{C}$ & 73,059 & 22,899 & 0,144 & 0,128 & 0,733 & 68,449 & 25,545 & 0,294 & 0,227 & 1,736 \\
\hline
\end{tabular}

Table 1 indicates that the correlation between temperature and solid yield of the pyrolysis results lies in the shrinking of the particles, resulting in a decrease in mass. The reduction of mass is significant compared to the decrease in volume, due to the effect of cavities' reduction, causing the enlargement of cavities in the char. As illustrated by the EDX results, changes are also depicted in the percentage of elements before and during pyrolysis at $350{ }^{\circ} \mathrm{C}$ and $650{ }^{\circ} \mathrm{C}$. It is apparent that the Carbon (C) bonding has a greater concentration compared to other elements, while Oxygen $(\mathrm{O})$ has a relatively smaller concentration percentage. At higher pyrolysis temperatures, more $\mathrm{C}$ is left as char, generating higher pyrolysis T to produce the increased calorific value of char (Wijayanti W., 2014). Even though char mass decreases along with the increasing pyrolysis temperature, the $\mathrm{C}$ percentage will increase if compared to the total elements, as presented in the element concentration in Table 1. For the concentration of inorganic compounds such as $\mathrm{Si}, \mathrm{S}$, and $\mathrm{Ca}$ contained in biomass, it is assumed as constant, due to small percentage. Typically, the Silicon concentration is found in ash; however, in this pyrolysis process, ash is not formed since there is no combustion reaction in the biomass due to suppression by the Nitrogen gas injected in the pyrolizers. Automatically, the percentage of Si concentration is almost fixed. Likewise, $\mathrm{Ca}$ content is relatively small despite presenting increased temperature.

Furthermore, the $\mathrm{O}$ element significantly decreases, which is inversely proportional to $\mathrm{C}$. In general, the characteristic of char is strongly influenced by the pyrolysis temperature, which greatly affects its final product and biomass decomposition. The biomass decomposition changes before and after pyrolysis process, resulting in significant differences in its composition, especially the composition of $\mathrm{C}$ and $\mathrm{O}$, in which $\mathrm{O}$ and $\mathrm{C}$ ratio serves as an indicator to analyze the characteristics of char through pyrolysis results (Jindo et al., 2014). Figure 6 illustrates Carbon 
concentration that increases while Oxygen decreases. If the pyrolysis temperature increases, the level of carbonization in the biomass will also increase, indicating that char significantly loses water and functional groups containing $\mathrm{O}$ (Wang et al., 2015) forming various chemical bonds with $\mathrm{C}$ and $\mathrm{H}$ into $\mathrm{CO}, \mathrm{CO}_{2}$, and $\mathrm{H}_{2} \mathrm{O}$. The result of the $\mathrm{C}$ chain on biomass breaks through the thermal cracking. The increase in energy to dissociate the biomass molecules bonding will be proportional to the increase of pyrolysis temperature, emphasizing that thermal cracking energy is pivotal for pyrolysis temperature. Generally, the main reaction that occurs includes the dissociation of $\mathrm{C}$ bonding, in which $\mathrm{C}$ will lose its electrons and become reactive, generating decarboxylation reaction. Such dissociation leads to the loss of the carboxyl group and releases $\mathrm{CO}_{2}$. In addition, dehydration reaction in the pyrolysis process releases $\mathrm{H}_{2} \mathrm{O}$. Therefore, as the pyrolysis temperature increases, the produced char will increasingly release Oxygen, resulting in better quality of produced char due to the decreasing ratio of O/C. Subsequently, this outcome determines the char heating value. Furthermore, the increasing Carbon concentration leads to an increase in char heating values, contained in solid yields which are potential as a fuel.

\section{The heating value of char yields}

Figure 7 indicates that the increase in pyrolysis temperature is almost linear with the increase in char heating value. The increasing temperature affects the high thermal energy for decomposing the bonds in biomass molecules, leaving a fairly large percentage of Carbon concentration. In tobacco, the long Carbon chain both in stems and leaves will be broken down by thermal energy. Even though it will reduce the yields of formed char, it will increase the amount of the remaining fixed Carbon, which results in the increase of heating value. The presented figure also indicates that the heating values for the tobacco stems and leaves before pyrolysis process are plotted with dashed lines, which are further compared to the heating values of the tobacco stems and leaves after being pyrolyzed at $350{ }^{\circ} \mathrm{C}, 450{ }^{\circ} \mathrm{C}, 550{ }^{\circ} \mathrm{C}$, and $650{ }^{\circ} \mathrm{C}$. In addition, the presented graph depicts that the caloric value of char from tobacco stems is much greater than that from tobacco leaves due to greater lignin content. As explained in a previous study (Wijayanti et al., 2013), lignin serves as a biomass compound that is difficult to decompose, leaving a large amount of fixed Carbon. This finding is proven by SEM-EDX test as displayed in Table 1 in which an increase in pyrolysis temperature leads to an increasing amount of fixed Carbon. Although the heating value of pyrolysis yields is far below the heating value before pyrolysis process, it should be noted that pyrolysis products are unlimited to char, but also include tar and gas, both of which also have heating values (Wijayanti et al., 2013). If the heating values of all pyrolysis yields are amounted, the heating value after pyrolysis process is much higher than the heating value of tobacco before pyrolysis. Figure 12 explains more regarding the heating value of tar. Meanwhile, gas products will be examined in subsequent studies.

\section{TAR YIELDS AS POTENTIAL LIQUID FUEL}

In addition to discovering products with the potential of becoming solid fuels, tobacco serves as liquid fuels in the form of tar yields. Additionally, the tar yield obtained in pyrolysis process is apparently found from the amount of liquid, trapped in the ice-cold trap as illustrated in Figure 1. Furthermore, Figure 8 demonstrates that higher pyrolysis temperature leads to higher mass of tar, soaring up to the temperature of $550{ }^{\circ} \mathrm{C}$ before later decreasing.

\section{The mass and density of tar yields}

The increasing tar yields were due to the thermal cracking among biomass molecules bonds, decomposed into tar and gas. In the condensed temperature at the ice-cold trap, the amount of liquid product (tar) increases while the gas remains outside due to the difference in the condensation point between liquid and gas. It is apparent that tar mass increases to the peak at $550{ }^{\circ} \mathrm{C}$ due to the thermal cracking effect and further decreases at $650{ }^{\circ} \mathrm{C}$ due to the secondary cracking reaction at temperatures over $600{ }^{\circ} \mathrm{C}$. Such raising cracking effect leads to tar and char products converted into gas due to the dominance of the secondary cracking reaction (Tripathi et al., 2016). Figure 8 depicts that the mass of tar yields from tobacco leaves is more significant compared to that from tobacco stem, indicating that higher content of hemicelluloses and cellulose in the biomass generates higher tar yields. In this study, because the tobacco leaves have greater amount of cellulose and hemicelluloses compared to the tobacco stems, the tar in tobacco leaves has greater mass than that in tobacco stems. 


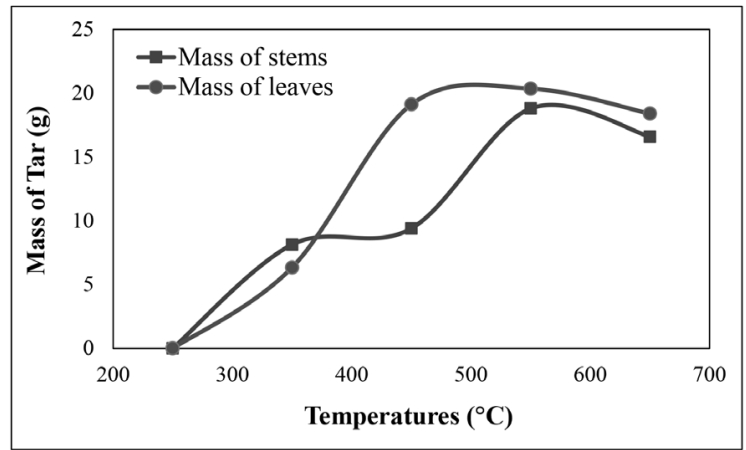

Figure 8. Mass of tar yields.

In contrast, as depicted in Figure 3, the char yields of tobacco leaves are higher compared to the tobacco stems due to the stem's lignin content. Figure 9 indicates similar pattern in the decline of the mass and volume in tar yields. Similarly, previous study (Jebet et al., 2018) investigated tar yields in pyrolysis process at temperatures ranging from $200{ }^{\circ} \mathrm{C}$ to $600{ }^{\circ} \mathrm{C}$. The produced tar yields indicated comparable results with this study, presenting similarity of gained yields. The peak amount of tar yields was achieved in a temperature of around $400^{\circ} \mathrm{C}$. In the experiment of this study, contrastingly, after $400{ }^{\circ} \mathrm{C}$, the tar yields slightly decreases, which differs from the aforementioned research finding suggesting a sharp decline.

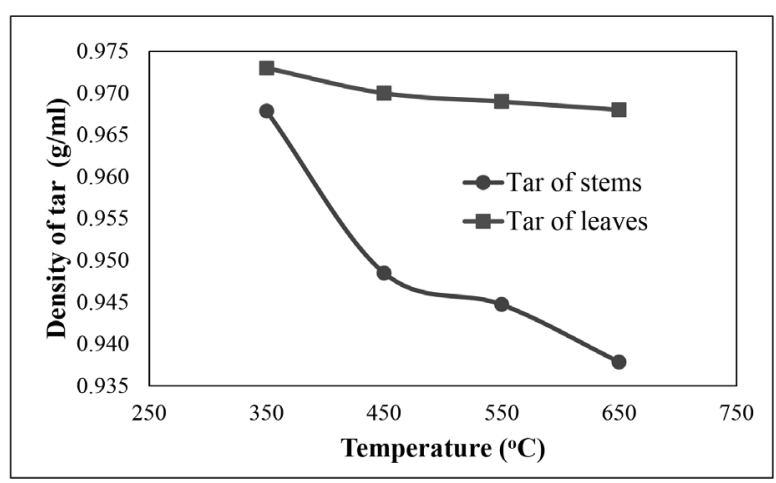

Figure 9. Densities of tar yields.

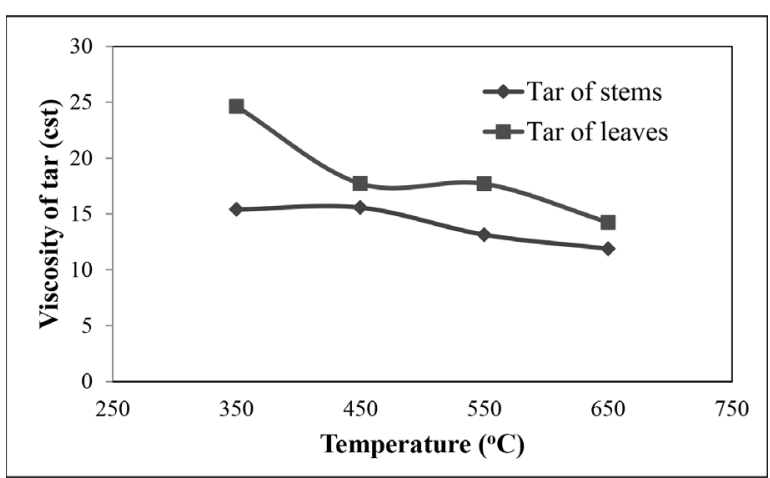

Figure 10. Viscosities of tar yields.

Meanwhile, measurements of tar properties were conducted to find out the quality and potentiality of the produced tar as a substitute for liquid fuels. In Figure 9, it is assumed that the increasing pyrolysis temperatures affect the reduction of tar density, indicating the lighter consistency of tar along with the decrease in tar mass in proportion to a certain volume. This result has a correlation with the viscosity of the generated tar as illustrated in Figure 10, indicating a decreasing trend of viscosity of tar. This result depicts that lighter tar yields will be produced in high temperatures as opposed to low temperatures. Hence, it is concluded that high temperatures will affect the cracking of biomass molecules, where the formation of tar results in shorter hydrocarbon chains. Consequently, tar will have a lighter mass and lower viscosity. Although the densities of tar in tobacco leaves are similar to those in tobacco stems, the tar densities of tobacco leaves are higher than those of tobacco stems. The small amount of tar density in tobacco stems is due to the difficulty of stem molecules to decompose as a result of high lignin content. The decomposition of the stem results in the least amount of tar yields, despite generating significant amount of char yields. A large amount of char causes the volatile matters generated by the pyrolysis process to be small in quantity. In fact, the volatile matters are the origin of tar and gas before being trapped in the ice-cold bath. As a result, the volatile matters of tobacco stems trapped in the ice-cold trap have shorter Carbon chains compared to the tobacco leaves. In this study, the density range 
of both stems and leaves is around $0.937-0.973 \mathrm{~g} / \mathrm{ml}$. Additionally, the density range of diesel engine fuel is included, which is around $0.8-0.96 \mathrm{~g} / \mathrm{ml}$.

\section{The viscosity of tar yields}

Figure 10 illustrates the decrease in the value of tar viscosity. Although tobacco stems and leaves present similar tendency with regard to their viscosity decrease, the tar from tobacco leaves has a greater viscosity than the viscosity of tar from tobacco stems. With similar heating energy, the large cellulose and hemicelluloses contents in tobacco leaves are more easily broken down into liquid yields containing longer Carbon chain bonds when compared to tobacco stems with less cellulose and hemicelluloses content, thus producing shorter carbon chains. In other words, a longer Carbon chain has a greater viscosity than a shorter carbon chain. In this case, the viscosities of pyrolyzed tobacco leaves are almost similar to those in tobacco stems. The pyrolyzed ones are around $12-25 \mathrm{cts}$, while the transformer oil has viscosities of around $20.2 \mathrm{cts}$. These results of the study reveal that the viscosities of tar yields have higher values compared to kerosene and diesel engine fuels, where similar cases occur on the flash point and the density of tar yields due to the influence of long Carbon chain inserted into tar yield decomposed from the tobacco. Furthermore, for the commercialization of liquid yields, fuel specifications are highly required as in the case of petroleum fuels. Thus, additional treatment such as distillation is encouraged in the event that it will be used as substitute oils.

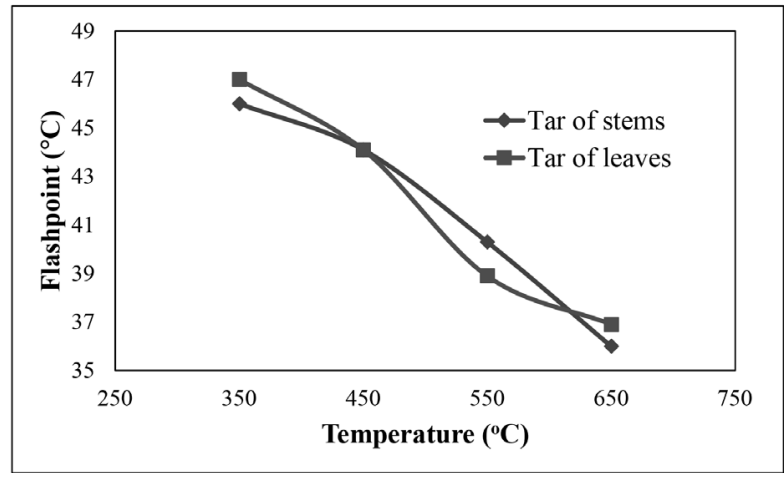

Figure 11. Flash points of tar yields.

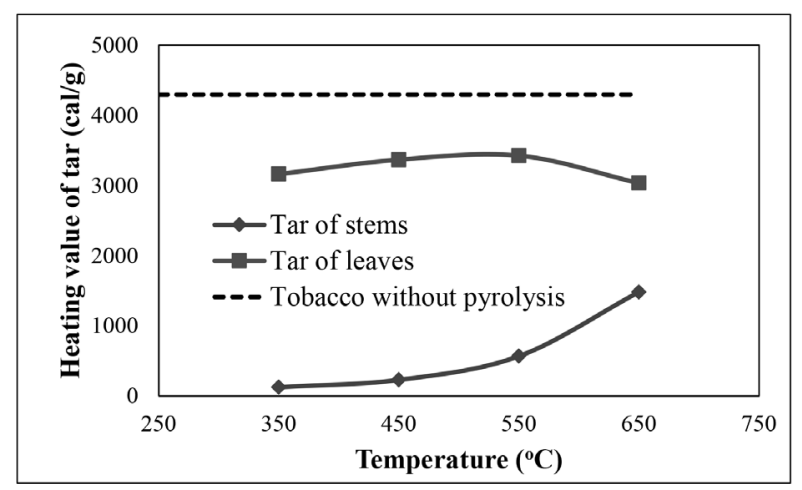

Figure 12. Heating values of tar yields.

\section{The flash point of tar yields}

Another crucial physical property that must be identified in any alternative fuels is the flash point. The flash point of tobacco stems and leaves presents similar downward trend when the pyrolysis temperature increases. The tar's flash point ranges from 36 to $47{ }^{\circ} \mathrm{C}$ which is similar to the flash point of kerosene at $38-72{ }^{\circ} \mathrm{C}$. Figure 11 illustrates that increasing pyrolysis temperature causes a decrease in flash point because it increases the thermal energy to break down some of the hydrocarbon molecules, leading to shorter Carbon chains in the produced tar. Hence, shorter carbon chain will have lower flash point due to lower activation energy to generate a combustion reaction in tar. The decreasing tendency of flash point is similar to the decreasing tendency of viscosity. The fuel with a lower viscosity also has a lower flash point due to shorter carbon chain of the fuel. This result affects the reduction of activation energy for combustion ignition. Furthermore, the decreasing tendency of tar in tobacco leaves' flash point is similar to that in tobacco stems, despite few instances where the tar in tobacco leaves has a higher flash point than that of tobacco stems due to differences in their components.

\section{The heating value of tar yields}

Similar to char yields, the heating value serves as an important property for tar due to the amount of energy contained in the fuel. In this study, the heating value of tar yields is lower than the heating value of the tobacco before pyrolysis. Then, the heating value of leave' tar yields is higher than stem's tar yields. This result is in contrast to the 
heating value of char, where the char' heating values have higher heating values than before pyrolysis' heating values. Hence, the heating value of stem' char is greater than leaves' char due to char contents in tobacco stem at the end of the pyrolysis process. Afterwards, Figure 12 illustrates the relationship between pyrolysis temperature and heating value of the produced tars.

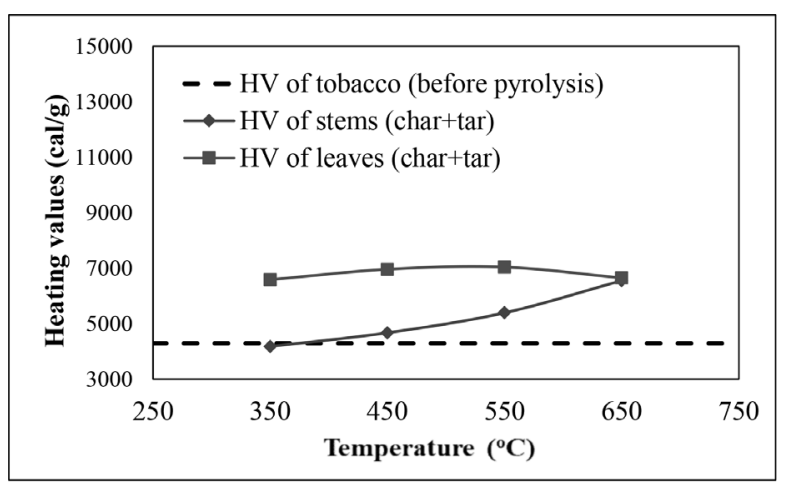

Figure 13. Heating values of char and tar yields.

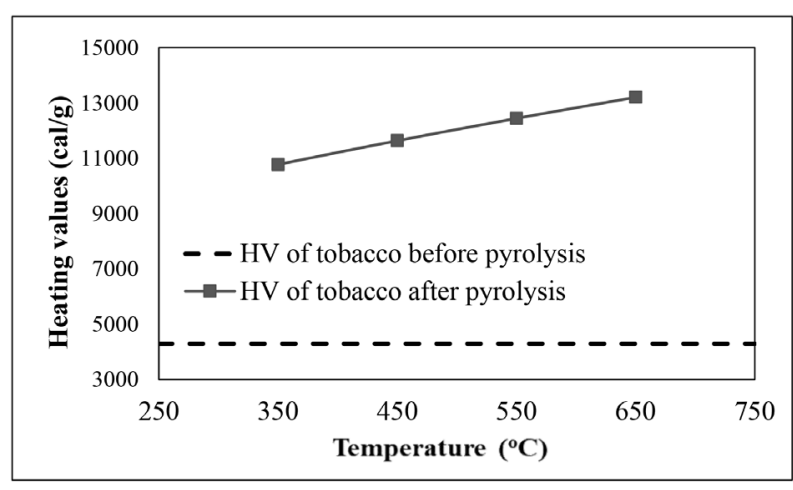

Figure 14. Heating values of tobacco crops.

The increasing pyrolysis temperature from $350{ }^{\circ} \mathrm{C}$ affects the heating values of the tar yields resulting in the lowest heating value on both tobacco stems and leaves due to thermal cracking. In addition, the hydrocarbon compounds (C-H) produce a number of compounds having a potentially high enthalpy of formation because of the presence of lignocellulosic (cellulose and hemicelluloses) structures which have different breakdown temperatures. Even though the heating value of tars from tobacco stems and leaves is low, the total amount of the heating values for both char and tar products as presented in Figure 13 has a high heating value, exceeding the heating value before pyrolysis process by a significant margin. Even if compared to the heating value of before and after pyrolysis process, the heating values indicate a significant pattern. Hence, it is assumed that if the gas values are also included in the pyrolysis results, tobacco will have the enormous heating value after undertaking pyrolysis process, as illustrated in Figure 14. At $650{ }^{\circ} \mathrm{C}$, the heating values of both char and tar reach more than $300 \%$ of the original value, indicating a significant increase. This pattern assumed that if the tobacco crop is converted into pyrolysis products, the energy increase can reach almost 300\%. However, it merely applies only if each yield has the same number of mass yields.

\section{ENERGY BALANCE OF TOBACCO PYROLYSIS}

By considering the energy balance equation, the amount of energy before and after pyrolysis process is obtained through the following equation:

$$
\sum E_{\text {in }}=\sum E_{\text {out }}
$$

in which

$\sum E_{\text {in }}$ represents the amount of energy before pyrolysis and $\sum E_{\text {out }}$ represents the amount of energy after pyrolysis. In this case, Equation 1 is substituted by using the number of moles, and the heating values are determined by

$$
\sum n . \sum H_{\text {tobacco }}=\sum n . \sum H_{\text {char }}+\sum n . \sum H_{\text {tar }}+\sum n . \sum H_{\text {gas }}
$$

in accordance with the conservation law of energy and mass, as stated in Equation 2, in which $n$ is mol and $H$ represents heating value of compounds. In real conditions, the number of $n$ will vary, whereas the $M r$ (molecular mass) of yields $\left(M r_{\text {char }}, M r_{\text {tar }}\right.$, and $\left.M r_{\text {gas }}\right)$ will also change depending on the pyrolysis temperatures. However, if assumed that the amount of biomass moles $\left(n_{\text {biomass }}, n_{\text {char }}, n_{\text {tar }}\right.$, and $\left.n_{\text {gas }}\right)$ has the same amount of moles, then the amount of 
heating values is similar to the measured heating values in this study. This assumption is due to the amount of mass as measured either for biomass, char, or tar which is similar for any measurement of properties including viscosity and flash point. Therefore, this assumption explains the reason of why the heating value of pyrolysis products is much higher than the biomass (before pyrolysis). When tobacco is directly burned, the potential used energy is not an optimal decomposition due to the strong bonds between the tobacco molecules, hindering some molecules to decompose. In contrast, if processed by pyrolysis, the tobacco can be decomposed into compounds with high energy content, having the potential as alternative fuels.

Furthermore, the investigation to obtain the optimum pyrolysis yields was performed in temperatures ranging from $350{ }^{\circ} \mathrm{C}$ to $650{ }^{\circ} \mathrm{C}$. The results of pyrolysis process in this study indicate that the highest temperature is able to produce the highest and the best products which are similar to the substituted fuels, despite requiring large amount of heating energy. Conversely, lower pyrolysis temperatures are proved to not produce the expected number of products. Therefore, in order to save the heating energy and to produce the optimum products, it is recommended that pyrolysis process is undertaken in temperatures ranging from $400{ }^{\circ} \mathrm{C}$ to $500{ }^{\circ} \mathrm{C}$.

\section{CONCLUSION}

The discovery of alternative fuels derived from tobacco crops after harvesting was investigated through the pyrolysis process as proposed in this study, concluding the following.

1. Due to thermochemical processes, the increase and decrease of all tobacco pyrolysis yields were affected by pyrolysis temperature. The results indicated that the fuel properties of tobacco crop yields after pyrolysis process significantly improved compared to those before pyrolysis process.

2. The tobacco stems consist of more lignin content than the tobacco leaves, generating relatively more superior results with regard to some fuel properties in char and tar yields, including the density and the heating values. Meanwhile, for liquid yields, both tobacco stems and leaves produced similar values of flash point and viscosity.

3. Solid yields generated from the pyrolysis process have significantly more potential heating values than that from coal. By considering the energy balance equation, the application of equal amount in char and tar mass, both in tobacco stems and leaves, provides the potential as alternative fuels achieving the heating value by $300 \%$.

4. Liquid yields of tobacco pyrolysis include flash point, density, and viscosity values which are similar to kerosene, diesel engine fuel, and transformer oil. However, further treatments are required if they are going to be used as substitute oil.

5. The optimum pyrolysis temperatures are recommended to be settled from $400{ }^{\circ} \mathrm{C}$ to $500{ }^{\circ} \mathrm{C}$ in order to attain the most optimum products.

\section{ACKNOWLEDGMENT}

This research was funded by the Indonesian Ministry of Research, Technology, and Higher Education and the Faculty of Engineering of Brawijaya University in 2019. The researchers present the unconditional gratitude to Fraghian Aldy Prasangga, Obi Nazari Gusmana, and Muhammad Reza Fadhila for the valuable contributions and also to other colleagues for the countless supports and suggestions for the accomplishment of this research. The authors also wish to acknowledge the tobacco feedstock provided by Tarutama Nusantara Agriculture Company, Jember, Indonesia.

\section{REFERENCES}

Biswas, l., Pandey, N., Bisht, Y., Singh, R., Kumar, J. \& Bhaskar, T. 2017. Pyrolysis of agricultural biomass residues: Comparative study of corn cob, wheat straw, rice straw and rice husk, Bioresource Technology, 237: 57-63.

Dhyani, V. \& Bhaskar, T. 2017. A comprehensive review on the pyrolysis of lignocellulosic biomass, Renewable Energy, 129: 695-716. 
Gao, W., Chen, K., Xiang, Z., Yang, F., Zeng, J., Li, J., Yang, R., Rao, G., \& Tao, H. 2013. Kinetic study on pyrolysis of tobacco residues from the cigarette industry, Industrial Crops and Products, 44: 152-157.

Jindo, K., Mizumoto, H., Sawada, Y., Sanchez-Monedero, M.A. \& Sonoki, T. 2014. Physical and chemical characterization of biochars derived from different agricultural residues. Biogeosciences, 11: 6613-6621.

Li, Y.H., Chang, F., Huang, B., Song, Y., Zhao, H., \& Wang, K. 2020. Activated carbon preparation from pyrolysis char of sewage sludge and its adsorption performance for organic compounds in sewage, Fuel, 266.

Ma, X., Liu, Y., Yang, S.C., Yang, Pan, Y., Xia, C. \& Sandra, N.N.A. 2020. An experimental study on the relationship of the weight loss and crack width of oil shale, Kuwait Journal of Science, 47(2): 82-87.

Meneses, L.R., Raud, M., Orupõld, K. \& Kikas, T. 2017. Second-generation bioethanol production: A review of strategies for waste valorisation, Agronomy Research, 15(3): 830-847.

Pena, J., Villot, A. \& Gerente, C. 2020. Pyrolysis chars and physically activated carbons prepared from buckwheat husks for catalytic purification of syngas, Biomass and Bioenergy, 132.

Qiang, L., Zhi, L.W. \& Feng, Z.X. 2009. Overview of fuel properties of biomass fast pyrolysis oils, Energy Conversion and Management, 50: 1376-1383.

Sfakiotakis, S. \& Vamvuka, D. 2018. Study of co-pyrolysis of olive kernel with waste biomass using TGA/DTG/ MS, Thermochimica Acta, 670: 44-54.

Silvy, N.F., Reza, M.S., Uddin, M.N. \& Akhter, M. 2018. Comparison between Different Components of Some Available Hardwood and Softwood in Bangladesh, IOSR Journal of Biotechnology and Biochemistry, 4(1): 01-05.

Torikaiu, K., Uwano, Y., Nakamori, T., Tarora, W. \& Takahashi, H. 2005. Study on tobacco components involved in the pyrolytic generation, Food and Chemical Toxicology, 43: 559-568.

Tripathi, M., Sahu J.N. \& Ganesan, P. 2016. Effect of process parameters on production of biochar from biomass waste through pyrolysis: A review, Renewable and Sustainable Energy Reviews, 55: 467-481.

Wang, S., Gao, B., Andrew, R., Zimmerman, Li, Y., Ma, L., Harris, W.G. \& Migliaccio, K.W. 2015. Physicochemical and sorptive properties of biochars derived from woody and herbaceous biomass, Chemosphere, 134: 257-262.

Wang, S., Wang, K., Liu, Q., Gu, Y., Luo, Z., Cen, K. \& Fransson, T. 2009. Comparison of the pyrolysis behavior of lignins from different tree species, Biotechnology Advances, 27(5): 562-567.

Wijayanti, W. \& Tanoue, K. 2013. Char Formation and Gas Products of Woody Biomass Pyrolysis, Energy Procedia, 32: 145-152.

Wijayanti, W. 2014. Gaining the Enthalpy of Solid Yields Formation in the Process of Waste Pyrolysis, Applied Mechanics and Materials, 493: 179-185.

Wu, W., Mei, Y., Zhang, L., Liu, R. \& Cai, J. 2015. Kinetics and reaction chemistry of pyrolysis and combustion of tobacco waste, Fuel, 156: 71-80.

Yan, B., Zhang, S. \& Chen, W., Cai, Q. 2018. Pyrolysis of tobacco wastes for bio-oil with aroma compounds, Journal of Analytical and Applied Pyrolysis, 136: 248-254. 